\title{
Continuous Vitamin D3 Supplementation Effectively Improves the Low Vitamin D Status in Children with Autism Spectrum Disorder
}

Noboru Hasegawa ${ }^{1^{*}}$, Miyako Mochizuki ${ }^{2}$, Takako Yamada ${ }^{3}$, Seiji Morimoto ${ }^{4}$ and Ikuko Nagaya ${ }^{5}$

${ }^{1}$ Graduate School of Nursing, Doshisha Women's College, Kodo, Kyotanabe, Kyoto, Japan

${ }^{2}$ Kyoto Bunkyo Junior College, Senzoku, Makishima-cho, Uji, Kyoto, Japan

${ }^{3}$ Department of Occupational Therapy, Bukkyo University, Higashitoganoo-cho, Nishinokyo, Nakagyo-ku, Kyoto, Japan

${ }^{4}$ Department of Occupational Therapy, Faculty of Health Sciences, Kyoto Tachibana University, Yamada-cho Oyake Yamashina-ku, Kyoto, Japan ${ }^{5}$ Department of Food and Nutrition, Gifu City Women's College, Hitoichibakitamachi, Gifu, Japan

\section{Abstract}

Background: We previously showed that vitamin D supplementation might ameliorate typical clinical symptoms in children with autism spectrum disorder (ASD). In this study we examined the effects on serum vitamin D status in ASD children of discontinuation of vitamin D3 supplementation after 9 months.

Methods: We enrolled 5 male and 1 female Japanese children with ASD and 5 male typically developing children, all aged 3 years. Serum 25 -hydroxy vitamin D, calcitroic acid and vitamin D binding protein were measured at 4 months after the end of supplementation with oral vitamin D3 oil (2 $\mu \mathrm{g} /$ day of vitamin D3, corresponding to twice the daily requirement) for 9 months.

Results: The 25-hydroxy vitamin D levels were $\geq 30 \mathrm{ng} / \mathrm{mL}$ (sufficient) in 1 child, $>20 \mathrm{ng} / \mathrm{mL}$ and $<30 \mathrm{ng} /$ $\mathrm{mL}$ (insufficient) in 4 children and $\leq 20 \mathrm{ng} / \mathrm{mL}$ (deficient) in 1 child after 9 months of vitamin D3 supplementation. No significant differences were seen in the results for the typically developing children. At 4 months after the end of supplementation, the number of children in the insufficient group decreased from 4 to 1 ( 3 became deficient), while the number in the sufficient group decreased from 1 to 0 ( 1 became insufficient). This distribution was the same as that prior to vitamin D3 supplementation. Most vitamin D in the body is known to be activated finally metabolized to calcitroic acid. The serum calcitroic acid level was the same as the 25-hydroxy vitamin D level after 9 months of supplementation. At 4 months after the end of supplementation, the serum calcitroic acid level was lower than the 25 -hydroxy vitamin $\mathrm{D}$ level. These results suggest that supplemented vitamin D is quickly converted to calcitroic acid. No difference was seen in the value of serum vitamin $\mathrm{D}$ binding protein.

Conclusion: These findings show that continuous vitamin D3 supplementation is effective for ameliorating clinical symptom in children with ASD.

\section{Introduction}

Autism spectrum disorders (ASD) are developmental disorders associated with a high individual and social burden, but their aetiology is poorly understood. The prevalence of ASD among 3-17 year-old children has suddenly increased, reaching $2.24 \%$ in a 2014 national survey in the United States [1]. The prevalence of ASD is likely to increase in Japan [2].

Vitamin D is a secosteroid associated with peripheral calcium homeostasis and nervous system function [3]. Vitamin D exists in two major forms, vitamin D2 from plants and D3 from animals. Both vitamin D2 and D3 are biologically inert and require activation through two hydroxylation processes involving 25-hydrooxylase (CYP2R1) and 1a-hydroxylase (CYP27B1), located in the liver and kidney, respectively [4]. 1,25-dihydroxyvitamin D (1,25OHD) is a biologically active metabolite produced by two hydroxylation reaction steps in the nervous system [5]. Most activated vitamin D is converted to calcitroic acid [6]. Vitamin D-binding protein transports $85-90 \%$ of circulating Vitamin D metabolites in serum [7].

Many cohort studies have shown low neonatal vitamin D to be a possible risk factor for ASD [8,9]. In one case report, Vitamin D supplementation led to significant reduction in core symptoms of ASD [10]. We previously reported that vitamin D supplementation for 9 months might ameliorate typical clinical symptoms in children with autism spectrum disorder [11]. However, to our knowledge there has been no study analyzing vitamin $\mathrm{D}$ status after a follow-up period. status in ASD children.

\section{Materials and Methods}

\section{Subjects and setting} original author and source are credited.

\section{Publication History:}

Received: June 09, 2020

Accepted: July 15, 2020

Published: July 17, 2020

\section{Keywords:}

Vitamin D, Autism spectrum disorder, 3-year-old children, Calcitroic acid, Vitamin D binding protein discontinuation of vitamin D3 supplementation on serum vitamin D

Prior to this study, approval was obtained from the ethics committee of Bukkyo University (project registration number in 2018: 7). We enrolled 5 male and 1 female Japanese children with ASD and 5 male typically developing children, all aged 3 years. The researchers were present at the child welfare institution (Mukunokien, Kyoto, Japan) where the study was conducted to assure the proper management of safety and confidentiality in the study. The manager of the institution invited parents to participate in the study, and all the children whose participation was requested from January 2019 to January 2020 were enrolled. All subjects took oral vitamin D supplements (Baby D ${ }^{\circledR} 200$ :

"Corresponding Author: Prof. Noboru Hasegawa, Graduate School of Nursing, Doshisha Women's College, Kodo, Kyotanabe, Kyoto 610-0395, Japan, Tel: +81774-65-8855, Fax: +81-774-65-8820; E-mail: nhasegaw@dwc.doshisha.ac.jp

Citation: Hasegawa N, Mochizuki M, Yamada T, Morimoto S, Nagaya I, et al. (2020) Continuous Vitamin D3 Supplementation Effectively Improves the Low Vitamin D Status in Children with Autism Spectrum Disorder. Int J Nurs Clin Pract 7: 326. doi: https://doi.org/10.15344/2394-4978/2020/326

Copyright: (C) 2020 Hasegawa et al. This is an open-access article distributed under the terms of the Creative Commons Attribution License, which permits unrestricted use, distribution, and reproduction in any medium, provided the 
Citation: Hasegawa N, Mochizuki M, Yamada T, Morimoto S, Nagaya I, et al. (2020) Continuous Vitamin D3 Supplementation Effectively Improves the Low Vitamin D Status in Children with Autism Spectrum Disorder. Int J Nurs Clin Pract 7: 326. doi: https://doi.org/10.15344/2394-4978/2020/326

Page 2 of 4

$5.0 \mu \mathrm{g} /$ day of vitamin D3 oil purchased from Morishita Jintan Co., Ltd., Osaka) for 9 months. We recruited typically developing children from among the authors' acquaintances.

\section{Serum $25 \mathrm{OHD}$, calcitroic acid and vitamin $\mathrm{D}$ binding protein}

Blood was collected by venipuncture and serum 25OHD concentrations were measured by Kyoto Microbio Laboratory (Kyoto, Japan). Calcitroic acid and vitamin D binding protein were analyzed using a commercially available chemiluminescent immunoassay kit (Cloud-Clone, Corp., TX, USA ) and ELISA kit (R\&D systems Inc., $\mathrm{MN}$, USA), respectively.

\section{Statistical analysis}

The differences between before and after discontinuation and before and after supplementation were evaluated using the Wilcoxon test. Otherwise, we used the $\mathrm{t}$-test. A p-value of $<0.05$ was considered to be statistically significant. Analyses were carried out using SPSS 21 for Windows (IBM, Japan).

\section{Results and Discussion}

\section{Study subjects}

The characteristics of the study subjects are shown in Table 1. Age was 3 years for all the ASD children (males, $n=5$ females, $n=1$ ) and typically developing children (males, $\mathrm{n}=5$ ). $\mathrm{Ca}$ and $\mathrm{iPTH}$ were within the normal range, but $25 \mathrm{OHD}$ was below the sufficient value $(\geq 30 \mathrm{ng} / \mathrm{mL}$ ) in ASD children and significantly lower than that in the typical developing children (Table 1).

\section{Change in serum 25OHD}

The 25-hydroxy vitamin $\mathrm{D}$ levels were $\geq 30 \mathrm{ng} / \mathrm{mL}$ (sufficient) in 1 child, $>20 \mathrm{ng} / \mathrm{mL}$ and $<30 \mathrm{ng} / \mathrm{mL}$ (insufficient) in 4 children and $\leq 20 \mathrm{ng} / \mathrm{mL}$ (deficient) in 1 child after 9 months of vitamin D3 supplementation. No significant difference was seen with levels in the typically developing children (Figure 1a). At 4 months after the end of supplementation, the number of children in the sufficient group decreased from 1 to 0 ( 1 became insufficient), while the number in the insufficient group decreased from 4 to 2 ( 2 became deficient). These were the same as the levels prior to vitamin D3 supplementation (Figure 1b).

\begin{tabular}{|l|c|c|c|}
\hline & $\begin{array}{c}\text { ASD before } \\
\text { supplementation }\end{array}$ & $\begin{array}{c}\text { Typically } \\
\text { developing children }\end{array}$ & p-Value \\
\hline $\mathrm{Ca}(\mathrm{mg} / \mathrm{dL})$ & $9.7 \pm 0.4$ & $9.6 \pm 0.2$ & n.s. \\
\hline $\mathrm{iPTH}(\mathrm{pg} / \mathrm{mL})$ & $25.0 \pm 8.8$ & $21.4 \pm 2.6$ & n.s. \\
\hline $25 \mathrm{OHD}(\mathrm{ng} / \mathrm{mL})$ & $22.6 \pm 5.5$ & $28.0 \pm 3.6$ & 0.013 \\
\hline
\end{tabular}

Table1: Characteristics of the study subjects (mean $\pm \mathrm{SD}$ ).

(b)

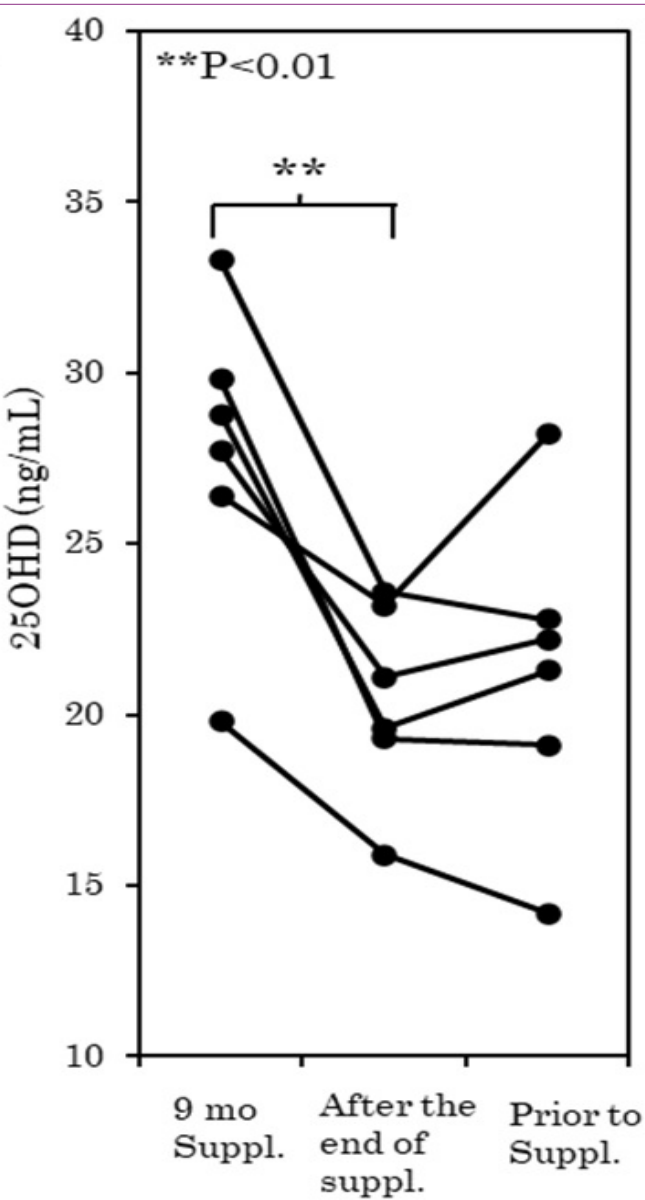
suppl.

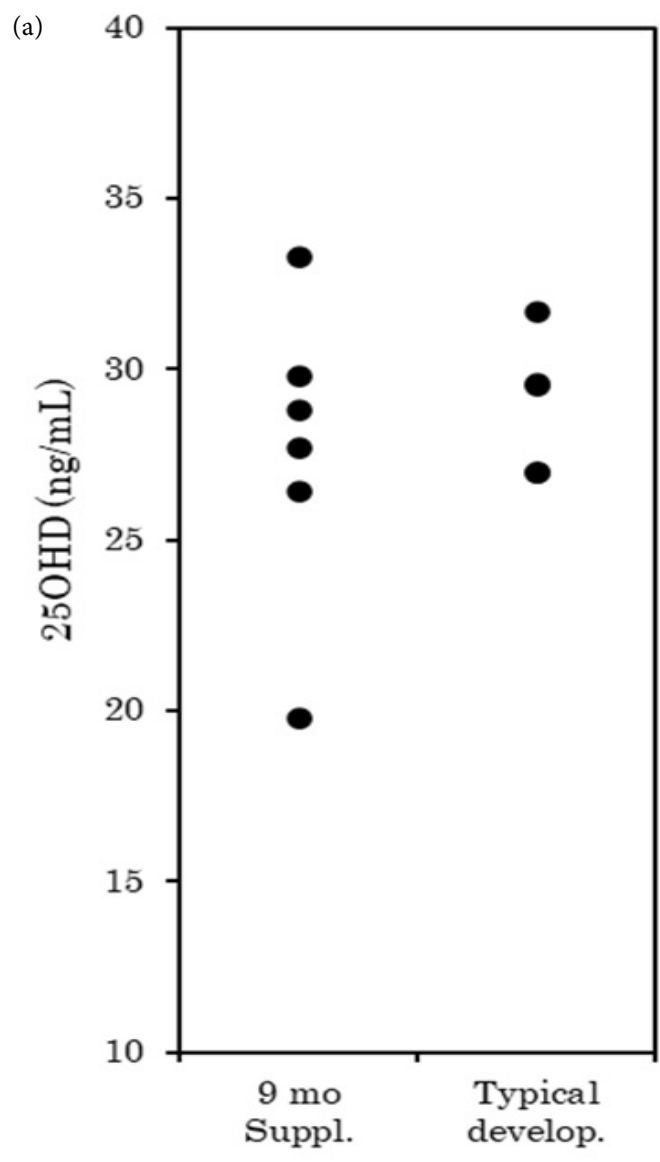

Figure 1: Serum 25OHD after 9 months of supplementation and at 4 months after the end of vitamin D3 supplementation. ${ }^{a}$ Comparisons of serum $25 \mathrm{OHD}$ between 9 months of supplementation and typically developing children.

${ }^{b}$ Comparisons of serum $25 \mathrm{OHD}$ between after the end of supplementation, 9 months of supplementation and prior to supplementation. 


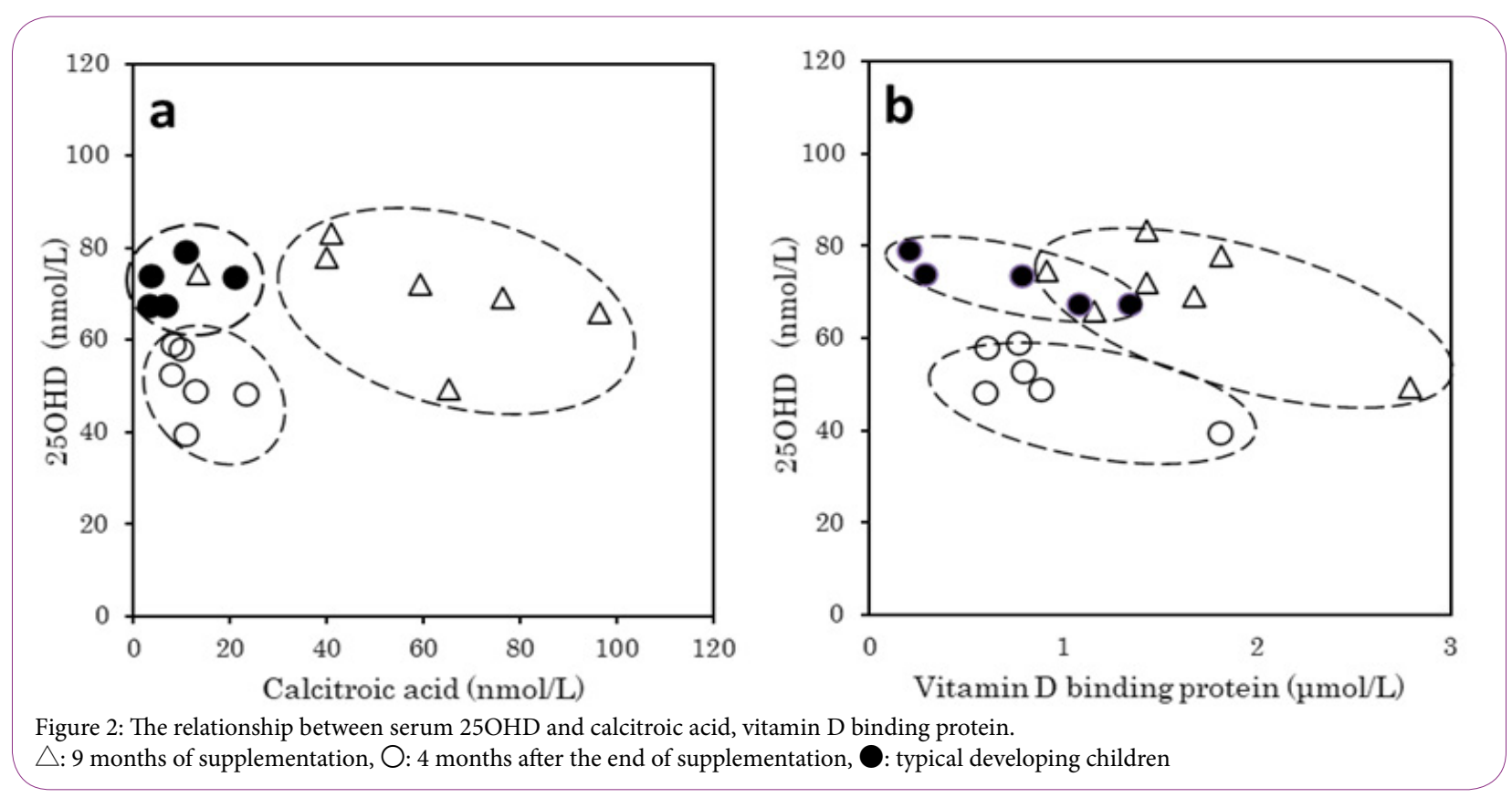

These results suggest that vitamin D3 supplementation increased serum 25OHD levels, and that they returned to the original levels after the vitamin D3 was discontinued.

Most vitamin $\mathrm{D}$ is known to be activated and metabolized to calcitroic acid [6]. In this study, the serum calcitroic acid levels were the same as 25-hydroxy vitamin $\mathrm{D}$ during supplementation. At 4 months after the end of supplementation, the serum calcitroic acid level was lower than the level of 25 -hydroxy vitamin $\mathrm{D}$. This tendency was similar to the result in typically developing children expect for high25-hydroxy vitamin $\mathrm{D}$ levels. These results suggest that supplemented vitamin D3 is quickly converted to calcitroic acid (Figure 2a).

A recent study pointed to the possibility that low vitamin $D$ levels in children with ASD are due to genetic factors associated with vitamin D metabolism [7]. It found the CYP2R1genotype is associated with a higher risk for ASD and with lower circulating form of vitamin D. These results suggest that supplemented vitamin D3 is not effectively transformed to 1,25OHD and metabolized to calcitroic acid. Vitamin $\mathrm{D}$ binding protein genetic variability is a significant factor affecting childhood vitamin D status [12]. In this study, no difference was seen in the value of serum vitamin $\mathrm{D}$ binding protein levels (Figure $2 \mathrm{~b}$ ).

This is a preliminary study with a very small number subjects. Further study with larger numbers of subjects is warranted, and could reveal optimal 25OHD levels for ameliorating ASD symptoms.

\section{Conclusion}

These findings indicate that continuous vitamin D3 supplementation is essential for improvement of the low vitamin D status in children with ASD.

\section{Competing Interest}

The authors declare that they have no competing interest.

\section{Author Contributions}

Dr. Hasegawa was responsible for the study conception, design, analysis, interpretation of data, and drafting of the manuscript.

Ms. Mochizuki was responsible for data acquisition and proof reading of the manuscript, and she participated in the data analysis.

Dr. Yamada was responsible for the data acquisition and proof reading of the manuscript.

Dr. Morimoto was responsible for the data acquisition and proof reading of the manuscript.

Ms. Nagaya was responsible for data acquisition and proof reading of the manuscript.

\section{Acknowledgements}

The authors acknowledge Ms. Chizu Shibuya and Ms. Fumie Fukuda for their kind help.

\section{References}

1. Zablotsky B, Black LI, Maenner MJ, Schieve LA, Blumberg SJ, et al. (2015) Estimated prevalence of autism and other developmental disabilities following questionnaire changes in the 2014 National Health Interview Survey. Natl Health Stat Report 13: 1-20.

2. Honda $H$, Shimizu $Y$, Imai $M$, Nitto $Y$ (2005) Cumulative incidence of childhood autism: a total population study of better accuracy and precision. Dev Med Child Neurol 47: 10-18.

3. DeLuca GC, Kimball SM, Kolasinski J, Ramagopalan SV, Ebers GC, et al. (2013) Review: the role of vitamin D in nervous system health and disease. Neuropathol Appl Neurobiol 39: 458-484.

4. Sarfraz Z (2015) Vitamin D: A Hormone. In: Sarfraz Z (Ed) Power of Vitamin D (3rd edition), Create Space Independent Publishing Platform, USA.

5. Garcion E, Wion-Barbot N, Montero-Menei CN, Berger F, Wion D, et al. (2002) New clues about vitamin D functions in the nervous system. Trends Endocrinol Metab 13: 100-105. 
Citation: Hasegawa N, Mochizuki M, Yamada T, Morimoto S, Nagaya I, et al. (2020) Continuous Vitamin D3 Supplementation Effectively Improves the Low Vitamin D Status in Children with Autism Spectrum Disorder. Int J Nurs Clin Pract 7: 326. doi: https://doi.org/10.15344/2394-4978/2020/326

6. Yu OB, Arnold LA (2016) Calcitroic acid - a review. ACS Cheml Biol 11: 26652672.

7. Schmidt RJ, Hansen RL, Hartiala J, Allayee H, Sconberg JL, et al. (2015) Selected vitamin $D$ metabolic gene variants and risk for autism spectrum disorder in the CHARGE study. Early Hum Dev 91: 483-489.

8. Fernell E, Bejerot S, Westerlund J, Miniscalco C, Simila H, et al. (2015) Autism spectrum disorder and low vitamin $\mathrm{D}$ at birth: a sibling control study. Molecular Autism 6: 3-9.

9. Schmidt RJ, Niu Q, Eyles DW, Hansen RL, Losif AM, et al. (2019) Neonatal vitamin $D$ status in relation to autism spectrum disorder and developmental delay in the CHARGE case-control study. Autism Res 12: 976-988.

10. Jia F, Wang B, Shan L, Xu Z, Staal WG, et al. (2015) Core symptoms of autism improved after vitamin D supplementation. Pediatrics 135: e196-e198.

11. Hasegawa N, Yamada T, Mochizuki M (2020) Vitamin D3 supplementation ameliorates typical clinical symptoms in children with autism spectrum disorder in Japan: A case study. Int J Nurs Clin Pract 7: 318-311.

12. Newton DA, Baatz JE, Kindy MS, Gattoni-Celli S, Shary JR, et al.(2019) Vitamin $D$ binding protein polymorphisms significantly impact vitamin $D$ status in children. Pediatric Res 86: 662-669. 